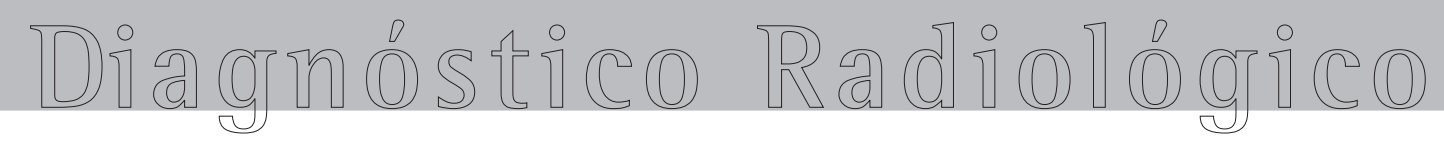

\title{
Diagnóstico do caso da edição anterior
}

\author{
J Bras Pneumol 2004;30(1):87
}

\section{Síndrome de Churg-Strauss (SCS)}
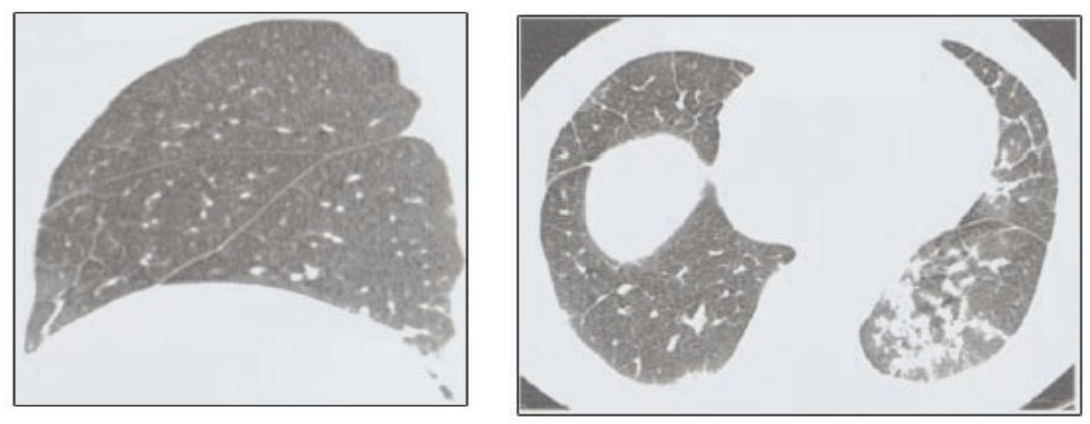

TOMOGRAFIA COMPUTADORIZADA DE ALTA RESOLUÇÃO (TCAR)

Exame realizado em equipamento multidetector de 16 canais com reconstrução multiplanar. As imagens axial e sagital demonstram espessamento dos septos interlobulares principalmente das regiões anteriores dos pulmões. Notase também espessamento peribroncovascular principalmente no lobo inferior esquerdo e esparsas áreas de opacidade em vidro fosco no pulmão esquerdo.

\section{COMENTÁRIOS}

A sindrome de Churg-Strauss (SCS) é uma doença multissistêmica rara, de causa desconhecida, caracterizada por combinação de alergia, eosinofilia sangüínea periférica, vasculite necrotizante, e inflamação granulomatosa extravascular. Quase todos os pacientes são asmáticos. Os principais sítios de acometimento sao pulmão, coração, pele e sistema nervoso. Pelo menos quatro dos seis seguintes critérios devem estar presentes para se estabelecer o diagnóstico: 1) asma , 2) eosinofilia maior que $10 \%, 3$ ) neuropatia, 4) opacidades pulmonares migratórias ou transitórias, 5) alterações nos seios paranasais, e 6) eosinófilos extravasculares em achados de biópsia.

Tradicionalmente, os achados histológicos consistem em vasculite necrotizante dos pequenos e médios vasos sangüineos associado a infiltração eosinofílica em torno dos vasos e tecidos adjacentes.

Os achados radiológicos são variados, sendo melhor avaliados na Tomografia Computadorizada de alta resolução (TCAR). 0 padrão mais freqüente na TCAR consiste em opacidades em vidro fosco ou consolidação do espaço aéreo bilaterais e esparsas acometendo principalmente as regiões pulmonares periféricas. Manifestações menos comuns incluem nódulos múltiplos ou solitários, que podem ocasionalmente cavitar, e espessamento do interstitício peribroncovascular e dos septos interlobulares. Este último achado pode ser secundário à falência cardíaca esquerda devido ao envolvimento cardíaco pela síndrome ou, menos comumente, relacionada à infiltração intersticial pulmonar eosinofílica. 0 paciente em questão apresentava função cardíaca normal e biópsia provando infiltração eosinofílica. Outras manifestações da SCS incluem derrame pleural unilateral ou bilateral e, raramente, linfonodomegalia mediastinal. Espessamento de paredes brônquicas e bronquiectasias podem ser encontrados, mas provavelmente refletem manifestações da asma, e não da síndrome de Churg-Strauss 
Num paciente asmático, o achado de espessamento septal interlobular, sem ou com associação com opacidades em vidro fosco ou consolidação, é sugestivo de síndrome de ChurgStrauss. A maioria desses pacientes responde bem a corticoidoterapia.

0 diagnóstico diferencial, neste caso, inclui, principalmente, edema pulmonar hidrostático secundário a insuficiência cardíaca e linfangite carcinomatosa.

\section{REFERENCES}

1. Fraser RS, Müller NL, Colman N, Paré PD. Diagnosis of diseases of the chest. Fourth edition. WB Saunders Company. Philadelphia, 1999.

2. Worthy AS, Müller NL, Hansel DM, Flower CDR. Churg-Strauss Syndrome: The spectrum of pulmonary CT findings in 17 patients. AJR 1998;170:297-300.

3. Johkoh T, Müller NL, Akira M, lchikado K et al. Eosinophilic lung diseases: Diagnostic accuracy of thin-section CT in 111 patients. Radiology 2000;216:773-780.

Acertadores do caso de Janeiro/Fevereiro 2004

André Luis dos Santos Becker - Hospital Fátima, Caxias do Sul, RS

Rubens Altair Amaral de Padua - Hospital Vaz Monteiro, Lavras, MG

Saulo Maia da Vila Melo - Hospital São Lucas, Aracaju, SE

Shirley Coletty dos Santos - Câmara dos Deputados, Brasília/DF 